\title{
Preliminary Investigation of the Economic Supervision System of PPP Project
}

\author{
Jiangfei Zheng \\ Department of Industrial Engineering, Tianjin University of Technology, Tianjin, 300384, China
}

email: 978753274@qq.com

Keywords: PPP project, whole process, government supervision, tracking audit

\begin{abstract}
Based on the research of audit experience of traditional government investment and construction projects and the current situation of carrying out the PPP projects blind and disorderly in China, this paper aims to show the incomplete structure, unspecific scope and the undefined emphasis of audit. According to the frequently-used domestic auditing methods, data processing methods and several different kinds of national standards of PPP projects in recent years show the economic supervisory work path and the economic supervision framework at different stages which applies the operation characteristics of the PPP projects during this time of China, and further clarifies the key and difficult points and specific contents of audit. This work may be helpful to safeguard the rights and interests of all stakeholders of the PPP projects, carry out the PPP projects orderly and promote the construction of national integrity, so as to provide the fundamental theory preventing from the loss of state assets.
\end{abstract}

\section{Introduction}

With the pressure of economic downturn in our country, to defuse the debt risk of local governments and to enhance the service supply capacity and efficiency of public projects, the promotion of PPP has become a strategic act to promote China's economic and social development ${ }^{11}$. In the country vigorously promote the implementation of the PPP model in all parts of the country in full swing PPP projects, but in some areas by the PPP Dongfeng to create performance, access to government policy support for the PPP project funds and other interests, the does not belong to or should not implement the PPP model project "forced Package "is PPP mode. Under the idea of "forced packing", third-party consulting agencies often make the project subjective by arguing that the project can pass the value-for-money and financial affordability assessment by modifying the pre-project measurement data. At present, various non-standard phenomena such as pseudo PPP or extended version BT have left hidden dangers to the future operation of the project, distorting our original intention of implementing PPP mode ${ }^{[2]}$. In-depth study and analysis of its due to the regulatory system is not in place, the audit system is not perfect. Under the condition of "forced packaging" flooding the construction market, how to construct the economic supervision framework and audit the PPP project has become an urgent problem to be solved.

\section{Problems Facing Economic Supervision of Investment Projects Constructed by Chinese Government under PPP Mode}

According to "13th Five-Year" National Audit Development Plan "clearly put forward to" strengthen the other government investment, government and social capital cooperation, construction of public goods and public service audit project ${ }^{[3]}$. With the implementation of the PPP project, some audit agencies Has been specifically involved in the audit of the audit of the PPP project, the basic tracking audit, but most are still in the exploratory stage to point with the current implementation of large-scale audit of the PPP project is still not perfect system of security, practical rules and guidance, Coupled with factors such as the contents, procedures, and subjects of the audit and supervision of the PPP project, and the incommensurability of the traditional audit model make the government of our country investing in construction projects facing enormous challenges. 


\subsection{Audit object is not clear}

The traditional government investment audit project participants in all the audit object, the audit department often take the construction unit as the starting point, and then in-depth other participating units, but rarely involved investors. Under the PPP mode, the project company, as the owner of the project, finances, constructs and operates the entire project. The project company can be formed jointly by the government and the social capital, or it can be the social capital alone. According to Cai Jin [2014] No. 113, social capital will turn non-state-owned enterprises into an investor role and possess the authority of the proprietor. Ignoring the auditing of investors will result in the omission of auditing and will make it easier for state-owned funds to be used at a lower rate.

\subsection{Audit coordination and communication difficulty}

Traditional follow-up audits usually start from the project initiation until the project is put into production or use for audit supervision. The follow-up audit for many years has gradually matured. Each participant of the project has a certain understanding of traditional follow-up auditing, lawful compliance of project operation and Comprehensive data to meet the audit requirements, coordination and communication more smooth. However, the use of the PPP model not only changed the project construction procedure, but also increased the identification, preparation, procurement, implementation and transfer of five stages, but also increased the complexity of project construction and management due to the entry of social capital, increased the project participants and enhanced The relationship between the parties involved has made it more difficult for audit departments to coordinate their communications when tracking and auditing PPP projects, which seriously hinders the audit department from achieving the audit result of $1+1>2$.

\subsection{Problems in the audit rectification difficulty}

From the actual situation of domestic PPP projects, some project companies and construction general contracting enterprises have their special relationship, in particular, take two standard and a standard way to obtain the project franchise investors, the emergence of investors that are athletes and It's a referee's situation. The project company did not play a central role in project management, did not give full play to its own advantages and added value to the project, resulting in one-sided pursuit of profit maximization by the project company, resulting in a low enthusiasm for the rectification of the problems found in the audit. At the same time, the audit content, the focus of audit and the immaturity of auditing methods have promoted the non-standard behavior of project companies during operation, thus reducing the government investment management level and the efficiency of using financial funds.

With the continuous popularization of the use of PPP mode, the traditional audit has been "unable to do anything". In the face of the current audit problem, in the audit of "full coverage" to become a new normal audit situation, the audit department should make the audit and the integration of various stages of the new model Innovative and innovative audit methods, seize the audit focus of all stages, give play to the "immune" role of audit, effectively regulate the infrastructure construction procedures and supervise the framework and achieve the goal of mutual benefit and win-win for all parties involved in investment. Therefore, we should establish a suitable China's Economic Supervision System ${ }^{[4]}$.

\section{Government departments in the PPP project economic monitoring framework and focus}

\subsection{The economic supervision framework of PPP projects}

The whole process of the PPP project in our country is divided into five phases: identification, preparation, procurement, execution and handover. The regulatory elements of each phase - the phases and elements match to form the regulatory matrix, and the audit department should have its positioning and responsibilities in the PPP project supervision matrix Division of labor. PPP projects should be subject to strict supervision by all parties. Supervision mechanism is reflected in 
two aspects: First, strengthen transparency, and second, establish a strict supervision and management system ${ }^{[5]}$. The purpose of this article is to clarify the regulatory time points and the contents of supervision of all government departments in the current regulatory matrix, and to extract the economic supervision methods of the audit department in the supervision of PPP projects.

\subsubsection{Project planning stage of the supervision framework}

The project planning phase includes the PPP project identification, preparation and procurement phases. At this stage, the main functions of government supervision are to determine whether project adoption, feasibility study, organization identification project can realize value for money using PPP model, rationality of project cost data, compliance of social capital choice, of social capital side signed a concession agreement and other aspects play a supervisory role. For the PPP project feasibility audit, we should combine with the financial status of the local government to see if there is a rush beyond the "financial affordability" to launch the PPP project ${ }^{[6]}$. Such as the NDRC, planning department, land department, the Ministry of Finance, the construction sector to play a major regulatory role at this stage, including the approval of project proposals and investment estimates, feasibility studies and approval of preliminary design proposals by the NDRC. The finance department presided over the demonstration of value for money and financial affordability reporting, monitoring the budget of PPP projects. The construction department regulates the access of building units and the entire construction process, such as the supervision of construction permits. However, the economic supervision and control of the audit department still needs improvement. The regulatory framework for the planning phase is shown in Figure 1.

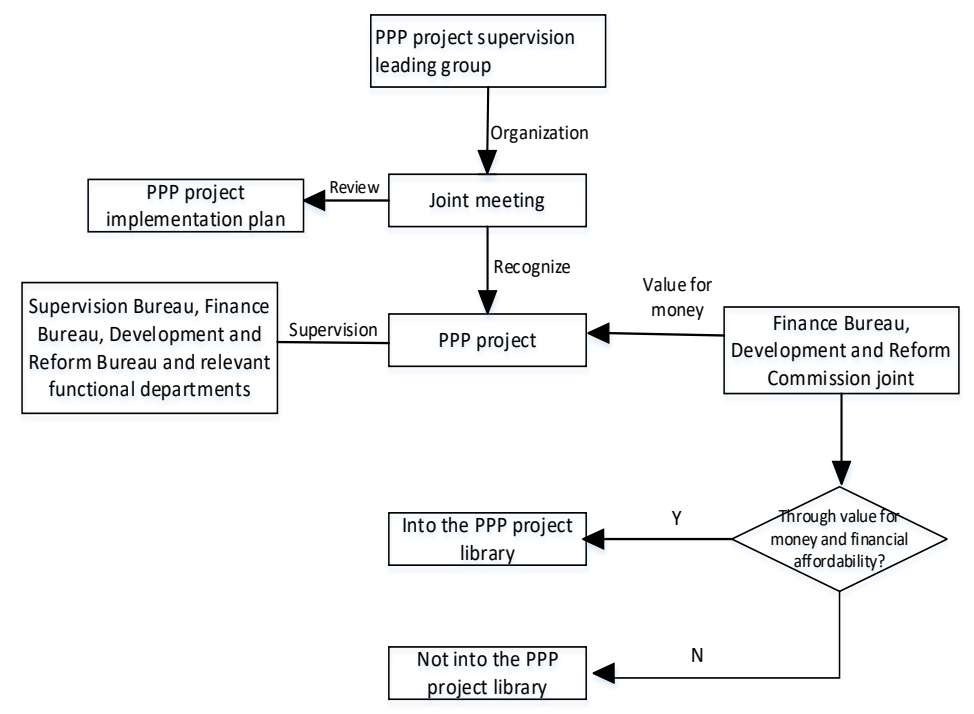

Figure 1 Supervision stage of the planning framework

\subsubsection{Supervision stage of the project construction phase}

The project construction phase refers to the construction period when the project company is established or each party fulfills the capital contribution obligation of the project according to the contract until the completion of the project or transfer of the project completion, that is, the construction phase of the PPP project. At this stage, progress of the project, quality of construction and funding are the key aspects of government supervision. The government tracks and supervises the key areas, leaving routine supervision and control to a comprehensive independent regulatory body so that all departments can coordinate with each other. The economic supervision of the audit department is particularly important. The audit department mainly audits and supervises the PPP project contract and its related engineering contracts, keeps track of key work such as payment and measurement of the audit price, supervises the entire financial status of all participants in the PPP project, Regulatory audit ${ }^{[7]}$. The regulatory framework of the project construction phase is shown in Figure 2. 


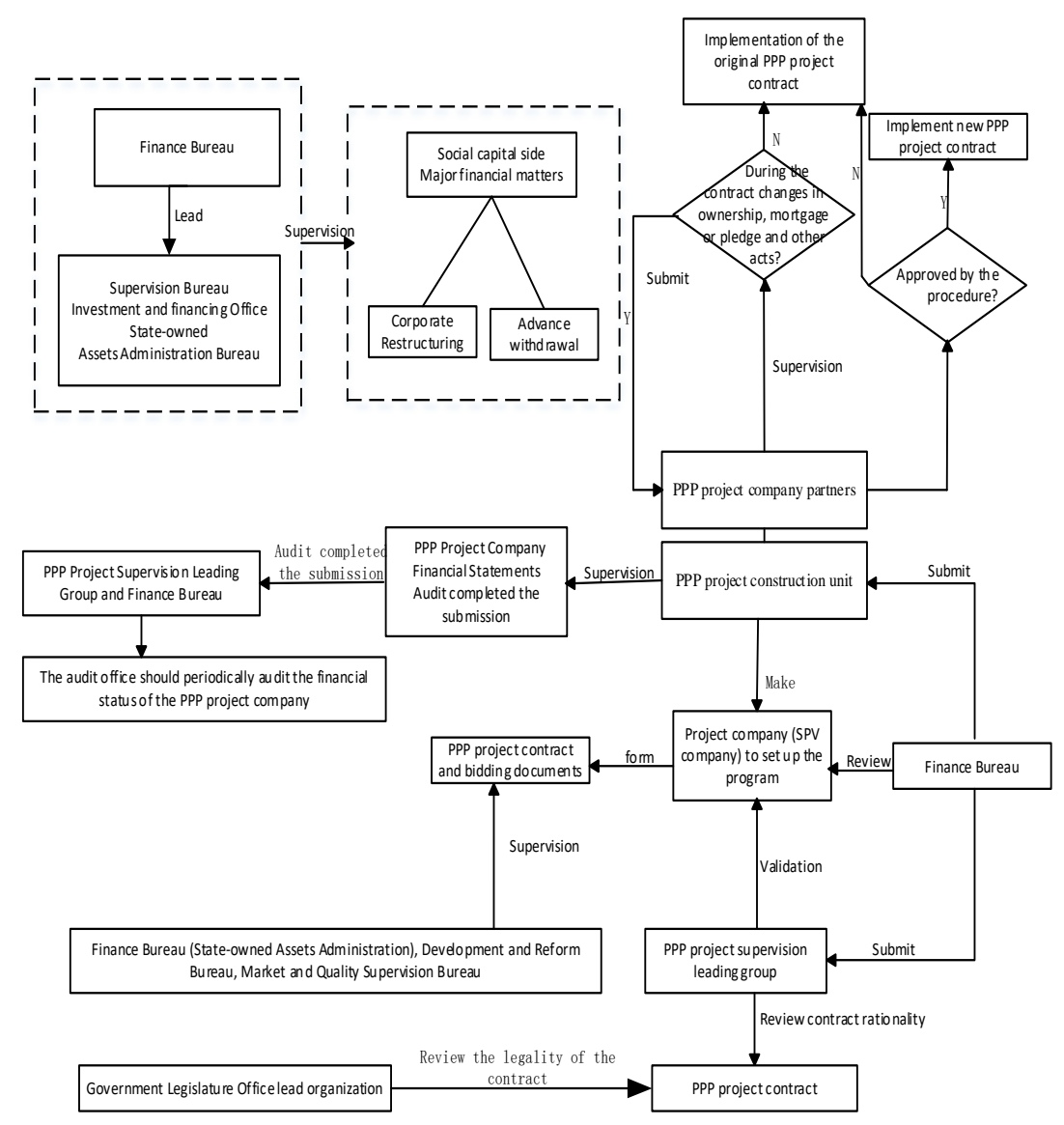

Figure 2 Project Construction Phase Supervision Framework

\subsubsection{Project Oversight Framework}

The project operation and maintenance phase refers to the period from the commencement of operation till the start of the handover work, that is, the operation period of the PPP project. This stage is the key period for the public goods and service quality inspection provided. The quality of service directly affects the satisfaction of users and directly affects the amount of performance-based payment. According to the provisions of the franchise contract, the project company shall do the project operation, maintenance and repair at this stage, ensure that the project meets the transfer standards when it is handed over, and the relevant work is supervised by the government regulatory department. Due to the bounded rationality of human beings, social capital will inevitably be driven by profit-making to raise the service charges or overload the infrastructure to increase operating income. Therefore, it is necessary to strengthen the supervision of the government at this stage. Particular attention to pricing mechanism or price adjustment mechanism and performance are closely linked to strengthen the supervision of the audit department pricing pricing. The monitoring framework of the project operation and maintenance phase is shown in Figure 3.

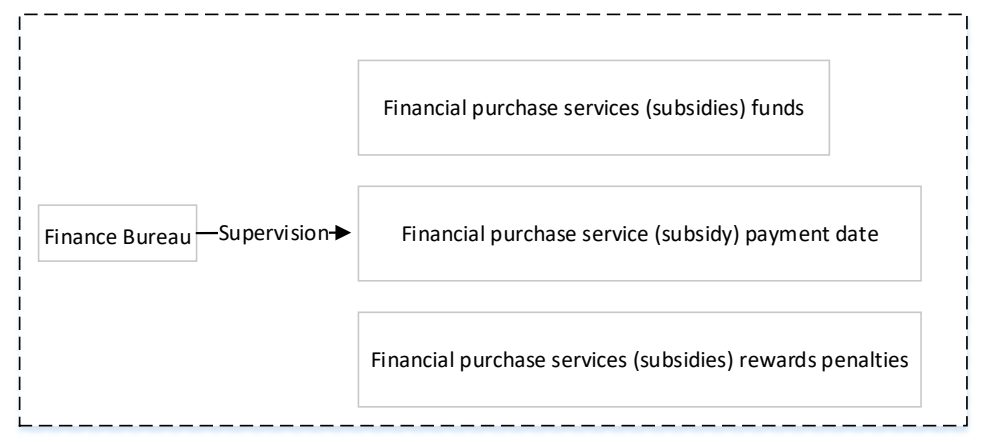

Figure 3 Project Operation and Maintenance phase of the monitoring framework 


\subsubsection{Regulatory framework of the project transfer phase}

The project transfer phase is the last link of the PPP project from the establishment of the transfer team to the end of the project handover. After the expiration of the concession, the project company hands over the ownership and management of the project to the government. When the project is handed over, the project company shall strictly transfer the scope of the project, the transfer standard and the transfer procedure in accordance with the contract. Therefore, the determination of the scope of the transfer, the criteria for the transfer of the regulatory authorities need to play a role, showing the importance of project supervision during the transfer stage. The implementing agencies and industry authorities supervise the project property rights, contract execution and transfer, assess the overall project and ensure the interests of both parties and public interests. The monitoring framework of the project transfer phase is shown in Figure 4.

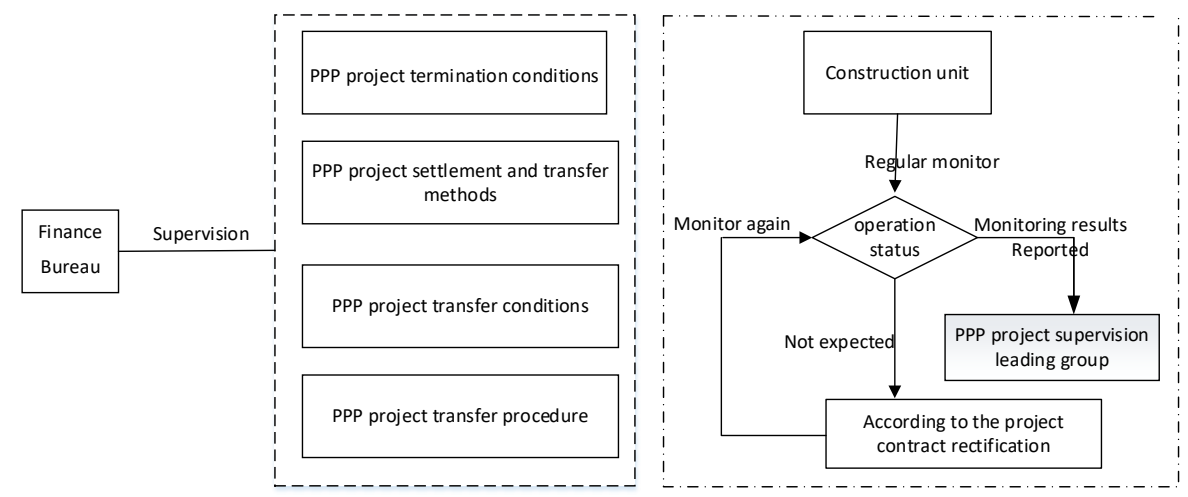

Figure 4 Project transfer phase of the monitoring framework

To sum up, regulation of PPP projects in China has initially formed a framework. However, with the non-standardization of PPP projects, the importance of stepping up the supervision of PPP projects has become increasingly prominent. In particular, it intensified the economic supervision of the PPP projects in the pre-operation and maintenance phases and strengthened the audit Department of the whole process of tracking the audit of the PPP project supervision, review and supervision of the use of project funds.

\subsection{Audit department in the PPP project economic supervision focus}

\subsubsection{Planning stage for the volume and price forecast data and substantive on tractual supervision of the economy}

(1) Project land

In reviewing the main points of "project land", the economic supervision department of PPP project should first distinguish the ways of obtaining land for the project and make it clear what the costs may be incurred. Furthermore, the transfer fee of the land for the project should be clarified. No matter whether the social capital is the first to acquire the land by way of assignment, the clarification of the land transfer fee is necessary because the land agreement transfer may occur in the process of construction. And then clear the cost of the project that includes the cost of the project costs will be on the future of government fees or users pay the impact. Through the above-mentioned monitoring process, it is possible to record the land use of specific projects for reference during the operation or handover phases.

(2) Investment scale and budget estimate

At this stage, the audit department can comprehensively use the review method, the calculation method and the review method for auditing. Reviewing the budget estimates and total investment of the project, mastering the basic information such as the investment scale of the project and the estimated budget of the project; reviewing the project construction documents of the audited entity, feasibility study and feasibility study approval documents, etc., and calculating the scale of the review project and whether the budget situation is consistent or not, whether there is an overvaluation or a lack of reduction. 
(3) Asset value and ownership

According to the Circular on Issues Concerning the Examination and Approval of the Administration of Franchised Foreign Investment Franchise Projects, the Measures for the Administration of Franchise in Municipal Utilities, the Guarantee Law and other relevant provisions, the auditing department strictly conducts the assessment of assets value and the management of related rights transfer, meanwhile, can be introduced to third-party asset evaluation agencies for review.

(4) Government commitment and supporting investment

In different PPP project contracts, the government promises to be likely to be found in different clauses. The government commitments that are more common in practice are as follows: 1 . Payments or subsidies; 2. Responsible for or assist in obtaining project-related land rights; 3. Provide relevant facilities and Supporting investment; Fourth, handle the relevant government approval procedures; Fifth, to prevent unnecessary competitive projects; Six other commitments. The audit department should conduct a review one by one, to avoid the emergence of government and other non-compliance measures, while supporting the verification of all the inputs to meet the post-review review requirements.

(5) project operation

In reviewing the operation mode of PPP project, we should sort out the operation mode of project according to the idea of embedding LCC, clarify the relationship of responsibilities, rights and interests in all aspects and match the actual situation of the project to determine whether the appropriate mode of operation has been chosen. For example, BOT mode, TOT mode, DBFO mode, such as the scope of the relevant specifications have been clear about the type of project. The supervisory department should comprehensively use the comparative analysis method and the review method to check whether the operation mode of the project meets the compliance requirements of the project's own characteristics and national regulatory documents and industry standards and prevent some investors from blindly determining the mode of operation of the project in pursuit of their own interests.

(6) Risk identification and sharing

On the risk side, the audit department needs to examine whether the risk identification of a specific PPP project is comprehensive and whether the risk sharing is reasonable and reasonable. Adopting the combination of risk inventory method and Delphi method, firstly, according to the actual situation of the project, the risk is exhaustively determined, and then the final risk is determined through the expert review of Delphi method. Optimal allocation of risk should seek to minimize project costs and risks by allocating specific risks to the control parties at the most advantageous locations ${ }^{[8]}$.

(7) Quantitative risk

In the process of economic supervision of PPP projects, it is necessary to examine whether the quantitative data of risk are reasonable and to recalculate the risk quantitative data according to the relevant quantitative methods, similar project experiences, the previous project databases and the local conditions of the project, such as the risk of force majeure such as earthquake The probability of occurrence and the amount of risk loss increase. Based on the above experience, the quantification of risk can be recalculated according to the calculation method to verify whether the calculation in the audited data is correct.

\subsubsection{Construction stage for the supervision of the actual cost data}

(1) PPP project construction process

The auditing of pre-approval procedures for construction projects is one of the important measures to ensure the scientific decision-making of the project, the feasible design and the reasonable scale. Strengthening auditing of audit procedures for construction projects can provide timely audit opinions on problems that may arise during the project decision-making process or problems that may arise, so as to ensure compliance with project compliance and law enforcement. Construction project audit focused on the process include: the integrity of the approval process, the 
authenticity of the approval document, the approval document compliance, the audit method targeted.

(2) Project budget, budget preparation and implementation

All preparation basis should be in line with the preparation of the state regulations to ensure the legitimacy of the preparation basis. Reviewing the project construction scale and standards; reviewing the estimated budget estimates, budget estimates, and tax rate applicability based on the national policies and policies in combination with the actual project conditions; reviewing the construction fee, equipment related and other construction projects Review the project "three wastes" governance programs and investments; review the preparatory expenses, loan interest, liquidity, etc .; review the comprehensive budget estimates and preparation; review the composition of budget documents; review the reasonableness of economic indicators. To establish and improve the financial management system is not only the requirement of regulating and perfecting its own financial management, but also an important guarantee for solving the financial regulatory problems [9].

\subsubsection{Operation and maintenance for monitoring project revenue and expenditure information}

(1) Balance sheet audit

According to the accounting system and relevant norms of auditing the preparation of the balance sheet, the use of comprehensive audit method of the current balance sheet amount compared with the previous period, focusing on whether there is a greater discrepancy, in which the abnormal situation to promptly check and Related statements and detailed analysis of the summary, the non-coincidence part as a key check, if necessary, should be combined with the current account of the inventory of inventory and fixed assets and other assets inventory, verify the authenticity of the report figures to ensure that the accounts The unity between the seamless.

(2) Income statement audit content

Audit the integrity of the income statement and normative, including whether the fill-in, wrong fill, missing items. Review the relationship between each figure in the income statement and other tables to verify that they are consistent. If there is a lack of correlation between the abnormalities in the figures and the income statement, further checks should be carried out in a timely manner. At the same time with the costs and expenses, sales income, profit distribution and other details of the tax and tax adjustments to verify the details of the cost, if found more or less deducted circumstances should be re-examined and verified, if necessary, to check the original voucher.

\section{Conclusion}

In 2015, it was praised as "the first year of PPP development" ${ }^{n[10]}$. Since the implementation of the PPP model in our country, especially in the past two years, the PPP model has undergone a spurt-style development ${ }^{[11]}$. The PPP project mainly provides public goods and services to the public. Public projects are funded by government and social capital. Eventually, the government pays the government through public resources or financial funds. Therefore, such projects must be included in the scope of government investment audit. The government audit department audits and supervises the authenticity and legitimacy of the financial data, the construction stage cost and the project company's financial, assets and liabilities during the planning stage of the PPP project, and makes objective and fair evaluation reports and resolutely defends the government and the Public interests, promote the building of a clean and honest government and prevent the loss of state assets.

It is necessary for the government auditing department to carry out economic supervision in the whole process of the PPP project. However, compared with the traditional audit of the whole process of government investment and construction projects, the economic supervision of PPP projects requires a broader audit, more professional fields involved, an earlier start of participation, and an economic oversight responsibility for government expenditures More meaningful. Based on the audit experience of traditional government investment and construction projects and the audit methods and data processing methods commonly used in China in recent years, this paper gives the 
economic supervision methods that conform to the characteristics of PPP operation in our country at present. In order to further approve and standardize the PPP project Economic supervision provides clear targeting.

\section{References}

[1] Lingzhi Sun, Hongjun Jia. Study on the Characteristics, Mechanism and Paths of Auditing and Supervision of PPP Model Construction Projects [J]. Audit Research, 2016 (02): 44-49.

[2] Shouqing Wang. PPP mode of response and challenges [J]. New Money - Corporate Finance, 2017 (1): 9-10.

[3] Ya Xu, Chi Zheng. Research on PPP Mode from the Perspective of Public Investment Auditing [J]. Financial Research, 2017 (6): 18-25.

[4] Xia Xu, Zhilin Zheng, Song Zhou. Research on government supervision system under PPP mode [J]. China Building Economy, 2015 (7): 105-108.

[5] Yilin Yin, Ling Yan. On the Construction, Organization and Implementation of Government Investment Projects and Their Supervision Mode [J]. Soft Science in China, 2003 (12): 12-17.

[6] Jiaojiao Zhou, Yu Pei. Analysis of the Audit Results of China's Departmental Budget Execution Based on Audit Announcements [J]. China Market, 2014 (39): 116-119.

[7] Liguo Wang, Ying Zhang. Tracking audit of PPP project [J]. Audit Research, 2016 (6): 30-35.

[8] Xiaojian Yan. Application of Public-Private Partnerships (PPPs) and Auditing Key Issues [J]. Audit Research, 2014 (5): 45-51.

[9] Xianzhuo Cheng. Strengthening the Financial Supervision Under the Mode of PPP Investment [J]. China Chief Accountant, 2017 (9) .12-14

[10] Yu Wang. China's PPP project performance audit mechanism [D]. Chongqing University, 2016.

[11] Yilin Yin, Ningming Xu, Jinhe Zhao. Discrimination on the PPP Mode with Franchise as the Core [J]. Project Management Technology, 2016, (8): 11-14. 